\begin{tabular}{|c|c|c|}
\hline $\begin{array}{c}\text { PORT SAID ENGINEERING RESEARCH JOURNAL } \\
\text { Faculty of Engineering - Port Said University } \\
\text { Volume } 14 \text { No. } 1 \text { pp: 159:164 }\end{array}$ & \\
\hline
\end{tabular}

\title{
DESIGN OF SUBSTRATE INTEGRATED CAVITY BACKED SLOT ANTENNA
}

\author{
Basma M. Abdel Wahed ${ }^{1}$, Atef Ghuneim ${ }^{1}$ and Hesham N. Ahmed ${ }^{2}$
}

\begin{abstract}
A cavity-backed slot antenna is thought to be one of the most suitable elements for the wireless transmission of microwave energy. A design procedure for single fed low profile high performance X-band cavity backed slot antenna is described in this paper. The whole antenna including, backed cavity and, feeding element is completely constructed on a single substrate by using substrate integrated waveguide (SIW) technique. A single grounded coplanar waveguide (GCPW) is employed as the feeding element to excite the $T E_{101}$ mode in the SIW cavity. An example is presented and the simulation results show $1 \%$ bandwidth, $5 \mathrm{dBi}$ gain, $18 \mathrm{~dB}$ front-to-back ratio and $88.44 \%$ radiation efficiency.
\end{abstract}

\section{INTRODUCTION}

Recently, the demand for low profile, compact and lowcost antennas with good radiation performance has experienced unprecedented development, along with growing interest for wireless technology, ranging from personal communications and entertainment to homeland security, tactical communications, and various other military applications. Technologies such as substrate integrated waveguide (SIW) allow for the implementation of compact, cost-effective waveguide-like structures using standard printed circuit board (PCB) techniques. SIW structures feature low loss, high quality factor, and can be easily integrated with planar circuitry [1].

Because of the great advantages of slot antennas, such as low profile, their conformability to planar or curved surfaces, easy integration with planar circuits, and better isolation from the feeding networks, they are used to develop wireless communication systems and have been extensively studied by many researchers [2]. But, due to their inherently bidirectional radiation properties, they all suffer from low radiation gain. In order to improve the radiation performance and eliminate the backside radiation, a shallow cavity is placed behind them. A simple short-end waveguide is usually served as backed cavity in slot antenna [3,4]. In [5], a method for reducing the cavity dimensions of a slot antenna backed by a rectangular cavity is presented. Conventional cavity backed slot antennas are conventional metallic cavity backed slot antennas which make them expensive to manufacture and they are still bulky for some applications. In order to reduce fabrication complexity and facilitate integration with planar circuits, the SIW technique is applied to cavity backed slot antenna designs. Antennas based on SIW are discussed in [6-9], with most of them

\footnotetext{
1 Electrical Engineering Department, Faculty of Engineering, Port Said University, Port Said, Egypt.

${ }^{2}$ Electronic Engineering Department, Military Technical College, Cairo, Egypt.
}

being similar to the conventional metallic waveguide slot array antennas. A low profile cavity, cavity backed, linearly polarized slot antenna using substrate integrated waveguide (SIW) technique has been firstly proposed in [10]. The entire antenna, including the radiating element, the feeding element, and the backed cavity, can be completely fabricated on a single layer substrate.

This paper presents a new SIW cavity-backed slot antenna based on the SIW technique combined with grounded coplanar waveguide (GCPW) structure. In the proposed structure, the properties of the cavity $\mathrm{TE}_{101}$ mode are exploited to obtain the smallest possible cavity, and low power loss. Furthermore, a designed SIW cavity resonator is presented in this paper that can be used in filter, diplexer, and oscillator design.

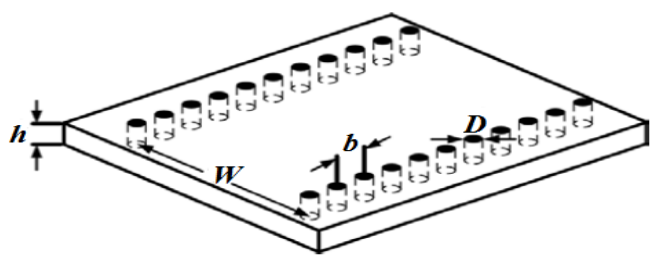

Fig. 1. Geometry of the SIW.

\section{SUBSTRATE INTEGRATED WAVEGUIDE CAVITY}

The SIWs are rectangular waveguides (RWGs) formed by two solid conductor planes, separated by a dielectric substrate, with conductor sidewalls emulated by rows of metalized through-plated vias [1]. The SIW structure is designed by choosing appropriately spaced vias, all with the same diameter " $D$ ", to sufficiently support guided wave propagation with a minimum of radiation loss. The spacing between the vias " $b$ " controls the amount of field leakage out of the waveguide. If the vias are spaced too far apart, the isolation property of the SIW will be compromised. The width of the waveguide " $W$ " is determined by the desired cutoff frequency of the dominant mode. To realize the 
minimum radiation loss as well as the return loss, the parameters of vias " $D$ " and " $b$ " should be kept as

$$
D / b \geq 0.5 \quad \text { and } D \leq 0.1 \lambda_{0} / \sqrt{\varepsilon_{r}}
$$

where $\lambda_{0}$ is the free-space wavelength and $\varepsilon_{r}$ is dielectric constant of the substrate. Figure 1 presents the geometric parameters for via diameter, via spacing, waveguide physical width, and substrate height as: $D, b, W$, and $h$, respectively.

Cassivi et al. [11] have used a generalized "Boundary Integral Resonant Mode Expansion" (BI-RME) method combined with the Floquet's theorem to obtain the propagation characteristics of SIW. They have demonstrated that the guided-wave characteristics of the SIW are equivalent to those of a conventional RWG with an equivalent width. They have shown that propagation properties of the $\mathrm{TE}_{10}$-like mode in the SIW are very similar to the $\mathrm{TE}_{10}$ mode of a rectangular guide. So, the initial size of the SIW cavity can be determined by the corresponding resonance frequency from [12] for the $\mathrm{TE}_{101}$ dominant mode, using the following formula:

$$
f_{101}=\frac{c}{2 \pi \sqrt{\mu_{r} \varepsilon_{r}}} \sqrt{\left(\frac{\pi}{W_{e f f}}\right)^{2}+\left(\frac{\pi}{L_{e f f}}\right)^{2}}
$$

where $W_{\text {eff }}$ and $L_{\text {eff }}$ are the equivalent width and length of the SIW cavity, they are expressed by:

$$
\begin{gathered}
W_{\text {eff }}=W-\frac{D^{2}}{0.95 \cdot b} \\
L_{\text {eff }}=L-\frac{D^{2}}{0.95 \cdot b}
\end{gathered}
$$

where $W$ and $L$ are real width and length of the SIW cavity. $D$ and $b$ are the diameter of the metallic vias and the distance between adjacent vias, respectively. $c$ is the speed of light in free space. $\mu_{r}$ and $\varepsilon_{r}$ are the relative permeability and relative permittivity of the dielectric substrate.

As mentioned in [13], there are three major loss mechanisms associated with SIW: dielectric loss, conductor loss and radiation loss. The unloaded quality factor of the cavity can be approximated by the following equation:

$$
\frac{1}{Q_{u}}=\frac{1}{Q_{c}}+\frac{1}{Q_{d}}
$$

where the quantities $Q_{c}$ and $Q_{d}$ are given in [14] for a rectangular waveguide cavity. Here, $Q_{c}$ is the quality factor due to conductor loss, which is determined by using effective dimensions of the SIW cavity in those formulas, permittivity of the dielectric, and the surface resistance of the metal $R_{s}$, whereas $Q_{d}$ is the reciprocal to the dielectric loss tangent $(\tan \delta)$.

The loaded $Q$-factor $\left(Q_{L}\right)$ of the SIW cavity is defined as

$$
Q_{L}=\frac{f_{0}}{\Delta f_{3-d B}}
$$

where $f_{0}$ is the resonance frequency and $\Delta f_{3-d B}$ is the $3-\mathrm{dB}$ bandwidth.

\section{ANTENNA CONFIGURATION}

Figure 2 shows the layout of the proposed SIW cavity backed slot antenna. The proposed antenna is completely constructed at a single substrate (RT/Duroid 5880 with relative permittivity of 2.2 , loss tangent of 0.0009 , and thickness of $0.787 \mathrm{~mm}$ ). The bottom side of this substrate is entirely covered with copper, and two rows of closely spaced vias are used to form the SIW cavity side walls. The radiating slot is etched in the bottom metal layer. Therefore, parasitic radiation generated by feeding network can be effectively isolated. To meet the requirement of planar integration, a single grounded coplanar waveguide (GCPW), which is allocated in the top copper plane, is employed as the feeding element, and is extended inside the cavity. A 50 $\Omega$ microstrip line of length " $L_{m s}$ " is coupled to the end of the GCPW center conductor. The length " $L_{c}$ " is used to convert the quasi-TEM of the microstrip line into the $T E_{101}$ of the SIW cavity. As the electric fields of both structures have the same orientation and profile, the transition design is easy to obtain.

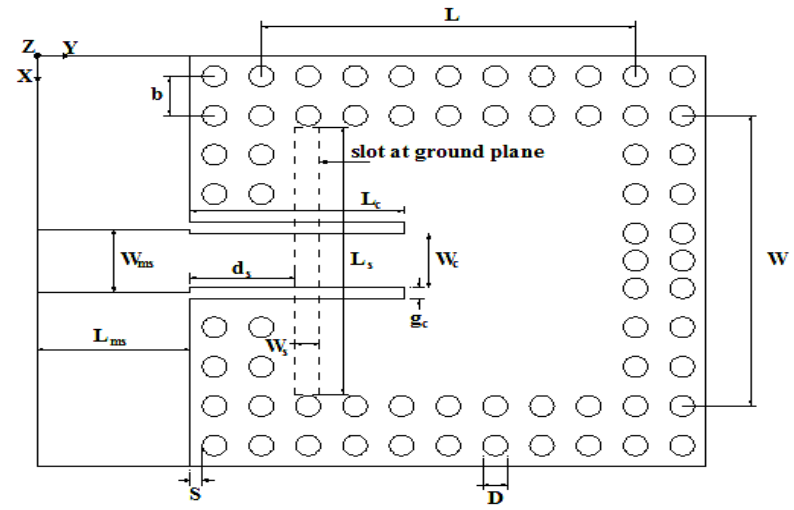

Fig. 2. Geometry of the proposed SIW cavity backed slot antenna.

Following the design principles described in the previous section, the proposed SIW cavity backed slot antenna is designed to operate at X-band. Detailed geometrical parameters of the proposed SIW cavity backed slot antenna are listed in Table 1.

Table 1 Geometrical parameters of the proposed SIW cavity backed slot antenna

\begin{tabular}{|c|c|c|c|}
\hline Parameter & Dim. $(\mathrm{mm})$ & Parameter & Dim. $(\mathrm{mm})$ \\
\hline $\mathrm{W}$ & 11.31 & $\mathrm{~L}_{\mathrm{c}}$ & 7 \\
\hline $\mathrm{L}$ & 12.21 & $\mathrm{~g}_{\mathrm{c}}$ & 0.45 \\
\hline $\mathrm{D}$ & 0.8 & $\mathrm{~L}_{\mathrm{s}}$ & 10.4 \\
\hline $\mathrm{S}$ & 0.4 & $\mathrm{~W}_{\mathrm{s}}$ & 0.8 \\
\hline $\mathrm{W}_{\mathrm{ms}}$ & 2.44 & $\mathrm{~d}_{\mathrm{s}}$ & 4 \\
\hline $\mathrm{L}_{\mathrm{ms}}$ & 5 & $\mathrm{~b}$ & 1.53 \\
\hline $\mathrm{W}_{\mathrm{c}}$ & 2.1 & & \\
\hline
\end{tabular}




\section{SIMULATED RESULTS AND ANTENNA PERFORMANCE}

The proposed antenna is simulated by using a commercial electromagnetic finite-element-based software packages, ANSOFT's High Frequency Structure Simulator (HFSS). The simulated return loss $\left(S_{11}\right)$ of the proposed antenna is shown in Fig. 3, in which dielectric and conductor losses have been taken into account. From Fig. 3, we can observe that the radiation is only obtained at the required frequency $(10.86 \mathrm{GHz})$ which makes the proposed antenna suitable for some applications in which highly isolated antenna is required for rejecting interference signal at out-band. Electric field diagram of the proposed antenna at $10.86 \mathrm{GHz}$ is given in Fig. 4. The radiation is generated by $T E_{101}$ in SIW cavity. The maximum electric field strength is at the center of the SIW cavity while magnetic fields surround the center of the cavity.

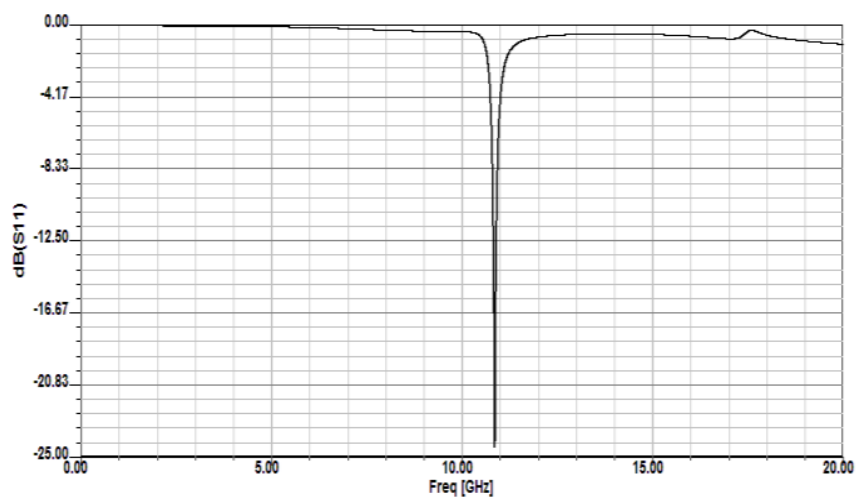

Fig. 3. Simulated $S_{11}$ of the proposed SIW cavity backed slot antenna.

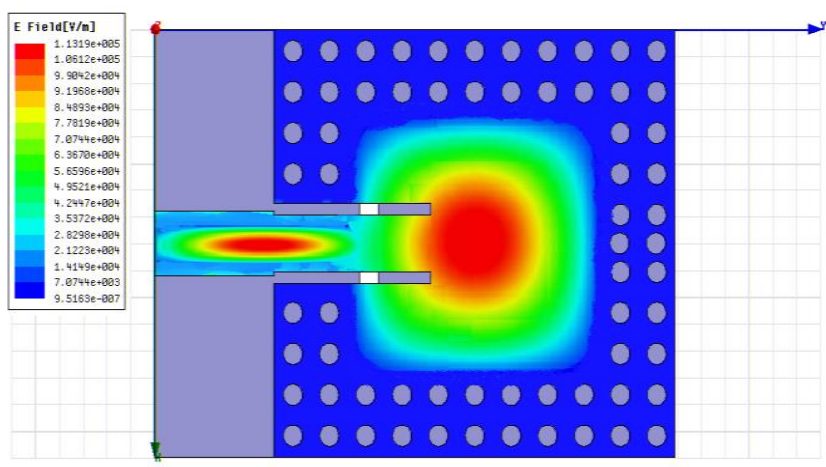

Fig.4. Electric Field Profile of the proposed SIW cavity backed slot antenna at $10.86 \mathrm{GHz}$.

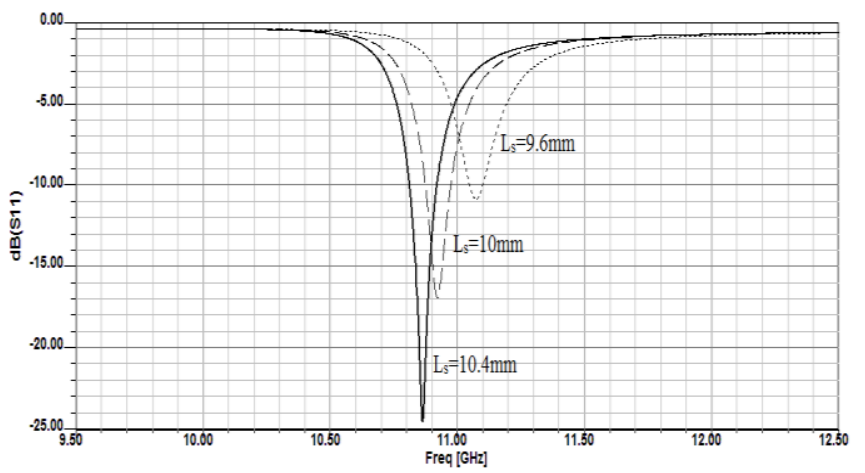

Fig. 5. Simulated $S_{11}$ of the proposed SIW cavity backed slot antenna vs. slot length $L_{s}$.

Table 2 Summary of simulated antenna parameters and impedance BWs with different slot lengths $L_{s}$ for 1-Watt input power

\begin{tabular}{|l|c|c|c|}
\hline & $\mathrm{L}_{\mathrm{s}}=9.6 \mathrm{~mm}$ & $\mathrm{~L}_{\mathrm{s}}=10 \mathrm{~mm}$ & $\mathrm{~L}_{\mathrm{s}}=10.4 \mathrm{~mm}$ \\
\hline $\begin{array}{l}\text { Central } \\
\text { Frequency }\left(\mathrm{f}_{0}\right)\end{array}$ & $11.07 \mathrm{GHz}$ & $10.92 \mathrm{GHz}$ & $10.86 \mathrm{GHz}$ \\
\hline BW\% & 0.45 & 0.91 & 1 \\
\hline Directivity & 2.934 & 3.233 & 3.155 \\
\hline $\begin{array}{l}\text { Radiated } \\
\text { Power }\left(\mathrm{P}_{\mathrm{r}}\right)\end{array}$ & $0.764 \mathrm{~W}$ & $0.8584 \mathrm{~W}$ & $0.88117 \mathrm{~W}$ \\
\hline $\begin{array}{l}\text { Radiation } \\
\text { Efficiency }\left(\mathrm{e}_{\mathrm{r}}\right)\end{array}$ & $83.28 \%$ & $87.64 \%$ & $88.44 \%$ \\
\hline
\end{tabular}

A slot antenna is usually viewed as an equivalent resonant magnetic dipole with its first resonance occurring at a frequency corresponding to an overall length of $\lambda_{\mathrm{g}} / 2\left(\lambda_{\mathrm{g}}\right.$ is the guided wavelength in the slot) [15]. The cavity was designed and simulated for a central frequency of $12.2 \mathrm{GHz}$. Once the slot is added, a central frequency of $10.86 \mathrm{GHz}$ and an impedance bandwidth of $1 \%$ are obtained. The impedance bandwidth of the proposed antenna is about $1 \%$, which makes it a narrow band antenna. This is a drawback of such low profile configuration antennas. In order to improve bandwidth some methods can be adopted. The impedance bandwidth of the proposed antenna can be gradually improved with substrate thickness " $h$ " increasing. Some other methods such as slot with inductive or capacitive load, and adding matching circuit in feeding network can be used to improve bandwidth too [10]. But, it is difficult for the proposed antenna have enough bandwidth for broadband application because it has unique responding mechanism. This unique responding mechanism makes it suitable for using in oscillators.

Figures 5 and 6 show that, the primary parameters that affect the performance and the frequency response of the antenna are the length and the width of the radiating slot $\left(L_{s}\right.$ and $W_{s}$ ). So, the radiating slot is an important tuning element of the proposed antenna. The simulated antenna parameters and impedance BWs with different slot lengths $L_{s}$ and different slot widths $W_{s}$ are summarized in Tables 2 and 3 respectively, from which we can observe that $L_{s}$ and $W_{s}$ can 
be used to change operating frequency, directivity, radiation efficiency and impedance bandwidth. As demonstrated in Fig. 7, any change in the slot position " $d_{s}$ " also will affect the antenna performance and the central frequency.

In Fig. 8, the simulated radiation patterns are shown. The far-field radiation patterns of the proposed SIW cavity backed slot antenna have been simulated at $10.86 \mathrm{GHz}$ in two different cut-planes, which correspond to E-plane $(x-z$ plane, $\left.\varphi=0^{\circ}\right)$ and H-plane $\left(y-z\right.$ plane, $\left.\varphi=90^{\circ}\right)$ respectively. The front- to-back ratio (FTBR) of the proposed antenna is about $18 \mathrm{~dB}$. The proposed antenna has radiation efficiency $\left(e_{r}\right)$ about $88.44 \%$ which is reasonable and suitable for using such type of antenna as the resonance element in oscillators.

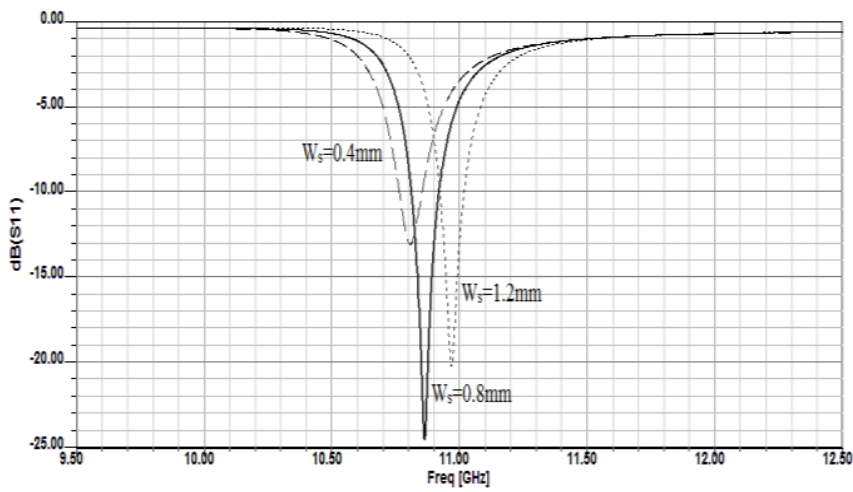

Fig. 6. Simulated $S_{11}$ of the proposed SIW cavity backed slot antenna vs. slot widths $W_{s}$.

Table3 Summary of simulated antenna parameters and impedance BWs with different slot widths $W_{s}$ for 1-Watt input power

\begin{tabular}{|l|c|c|c|}
\hline & $\mathrm{W}_{\mathrm{s}}=0.4 \mathrm{~mm}$ & $\mathrm{~W}_{\mathrm{s}}=0.8 \mathrm{~mm}$ & $\mathrm{~W}_{\mathrm{s}}=1.2 \mathrm{~mm}$ \\
\hline $\begin{array}{l}\text { Central } \\
\text { Frequency }\left(\mathrm{f}_{0}\right)\end{array}$ & $10.81 \mathrm{GHz}$ & $10.86 \mathrm{GHz}$ & $10.97 \mathrm{GHz}$ \\
\hline BW\% & 0.82 & 1 & 1.42 \\
\hline Directivity & 3.126 & 3.155 & 3.365 \\
\hline $\begin{array}{l}\text { Radiated } \\
\text { Power }\left(\mathrm{P}_{\mathrm{r}}\right)\end{array}$ & $0.82971 \mathrm{~W}$ & $0.88117 \mathrm{~W}$ & $0.83835 \mathrm{~W}$ \\
\hline $\begin{array}{l}\text { Radiation } \\
\text { Efficiency }\left(\mathrm{e}_{\mathrm{r}}\right)\end{array}$ & $87.33 \%$ & $88.44 \%$ & $84.65 \%$ \\
\hline
\end{tabular}

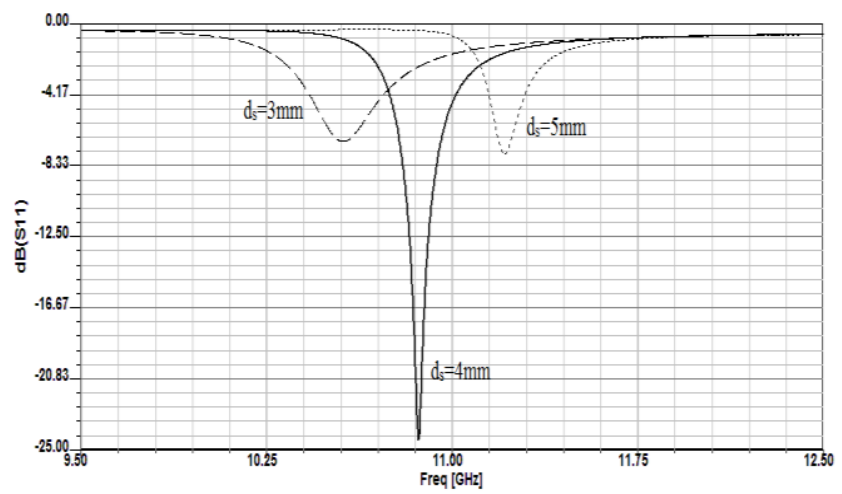

Fig. 7. Simulated $S_{11}$ of the proposed SIW cavity backed slot antenna vs. slot position $d_{s}$.

It should be noted from the simulated radiation performance of the proposed structure that its radiation performance is better than the radiation performance of conventional cavity backed antenna [3] with its profile greatly reduced. Its radiation performances are far better than that of conventional patch and slot antennas with the same low profile. Using the SIW cavity in our proposed antenna provides a very low profile as well as suppression of the surface wave and the backward radiation. Also, power leakage is greatly reduced, and edge diffraction effect is effectively suppressed. So, the radiation performance of the proposed antenna such as directivity, gain, FTBR, and radiation efficiency is evidently improved.

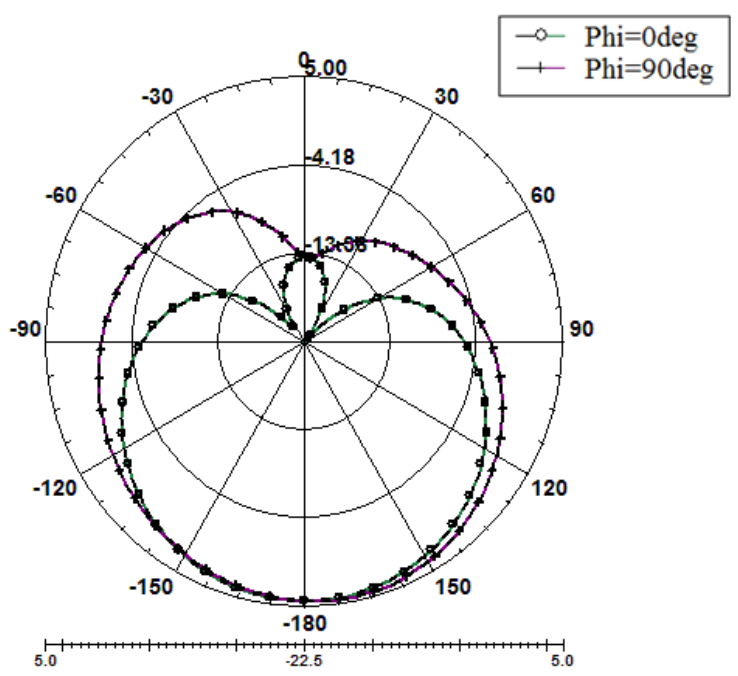

Fig. 8. Simulated radiation patterns of the proposed SIW cavity backed slot antenna in E-plane and H-plane at $f_{0}=10.86 \mathrm{GHz}$.

\section{SUBSTRATE INTEGRATED WAVEGUIDE CAVITY RESONATOR}

The SIW cavity resonator can be used in filter, diplexer, and oscillator design [16-19]. The proposed SIW cavity backed slot antenna can be considered as a resonator if the structure in Fig. 2 is modified to two port or two fed SIW 
cavity. As shown in Fig. 9, two GCPWs are employed as the feeding elements in the top copper plane. Each center conductor of the GCPW is coupled to $50 \Omega$ microstrip lines of length " $L_{m s}$ ". The final dimensions of the geometric parameters chosen for the design of the developed SIW cavity resonator are listed in Table 4.

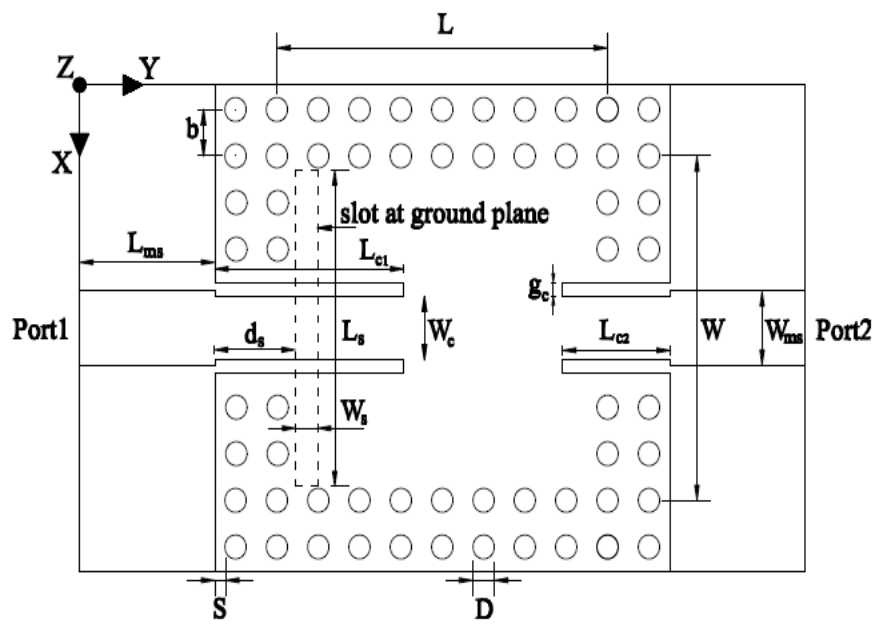

Fig. 9. Geometry of the proposed SIW cavity resonator.

Table 4 The Final dimensions of the geometrical parameters of the developed SIW cavity resonator.

\begin{tabular}{|c|c|c|c|}
\hline Parameter & Dim. $(\mathrm{mm})$ & Parameter & Dim. $(\mathrm{mm})$ \\
\hline $\mathrm{W}$ & 11.31 & $\mathrm{~L}_{\mathrm{c} 1}$ & 7 \\
\hline $\mathrm{L}$ & 12.21 & $\mathrm{~L}_{\mathrm{c} 2}$ & 4 \\
\hline $\mathrm{D}$ & 0.8 & $\mathrm{~L}_{\mathrm{s}}$ & 10.4 \\
\hline $\mathrm{S}$ & 0.4 & $\mathrm{~W}_{\mathrm{s}}$ & 0.8 \\
\hline $\mathrm{W}_{\mathrm{ms}}$ & 2.44 & $\mathrm{~d}_{\mathrm{s}}$ & 4 \\
\hline $\mathrm{L}_{\mathrm{ms}}$ & 5 & $\mathrm{~b}$ & 1.53 \\
\hline $\mathrm{W}_{\mathrm{c}}$ & 2.1 & $\mathrm{~g}_{\mathrm{c}}$ & 0.45 \\
\hline
\end{tabular}

After adding the second feeding element to the proposed antenna, the central frequency and the return loss $\left(S_{11}\right)$ have been affected as demonstrated in Fig. 10. So, the tuning length " $d_{s}$ " is changed from $4 \mathrm{~mm}$ to $3 \mathrm{~mm}$ to keep the return loss in good level.

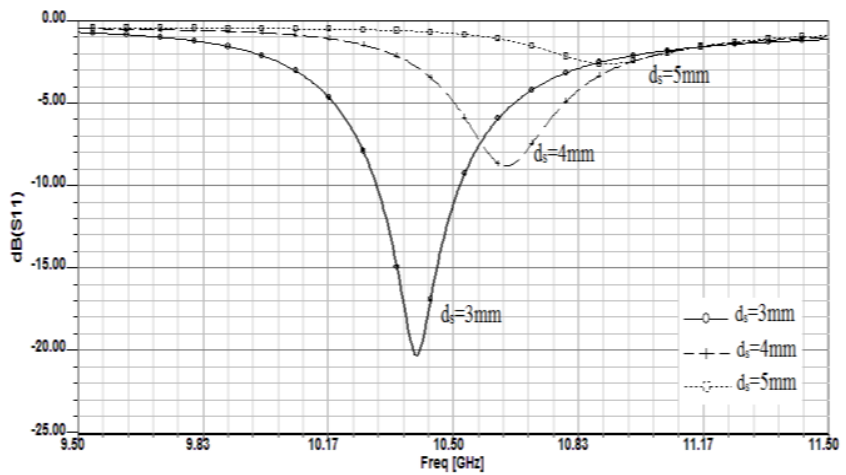

Fig. 10. Simulated $S_{11}$ of the developed SIW cavity resonator vs. slot position $d_{s}$.

Simulation results of the developed SIW cavity resonator are presented in Figs. 11 and 12, in which dielectric and conductor losses have been taken into account. Figure 11 shows the simulated return loss " $S_{11}$ " from which we observe that the radiation is only obtained at the resonant frequency $(10.4 \mathrm{GHz})$. Fig. 12 shows an insertion loss " $S_{21}$ " level of $2.65 \mathrm{~dB}$. Also, HFSS simulation results show an impedance BW of $2.13 \%$, a gain of $4 \mathrm{dBi}$, a directivity of 2.75 , and a radiation efficiency of $84 \%$.

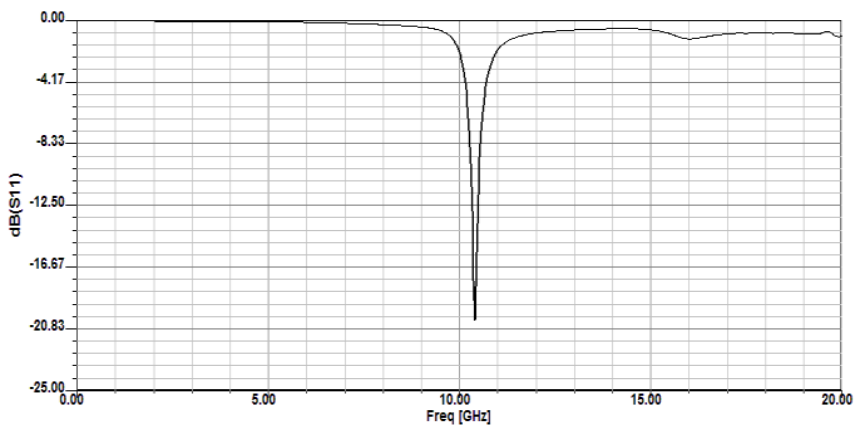

Fig. 11. Simulated $S_{11}$ of the proposed SIW cavity backed slot antenna.

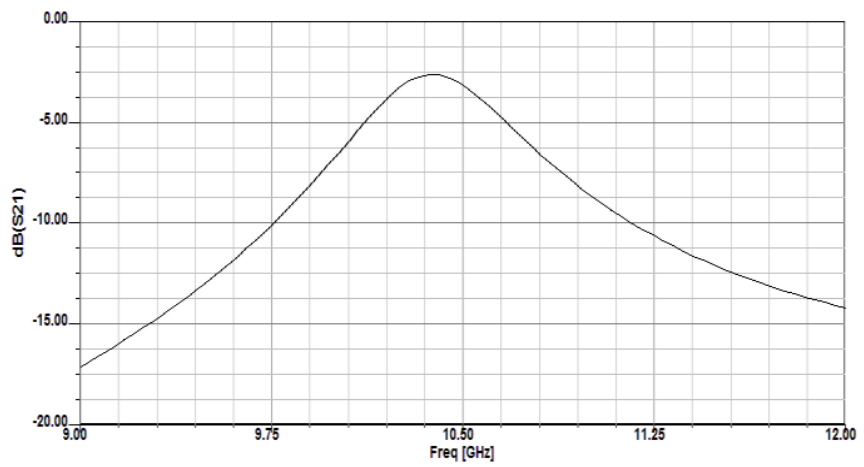

Fig. 12. Simulated $S_{21}$ of the proposed SIW cavity backed slot antenna.

\section{CONCLUSION}

A low profile high performance X-band SIW cavity backed slot antenna has been proposed. The proposed antenna is designed using ANSOFT's HFSS tool. The simulated antenna has $1 \%$ bandwidth and keeps high radiation performance of conventional cavity backed antenna such as high gain, high directivity, and high FTBR. It still has advantages of conventional planar antennas such as low profile, light weight, good conformability and integration with planar circuit. It can be easily fabricated by ordinary single layer PCB process with very low cost. It can be easily modified to a SIW cavity resonator to be used in filter, diplexer, and oscillator design.

\section{REFERENCES}


[1] W. Ke, D. Deslandes, and Y. Cassivi, "The Substrate Integrated Circuits - A New Concept for HighFrequency Electronics and Optoelectronics," presented at $6^{\text {th }}$ International Conference on Telecommunications in Modern Satellite, Cable and Broadcasting Service, 2003. TELSIKS 2003.

[2] R. Azadegan and K. Sarabandi, "A Novel Approach for Miniaturization of Slot Antennas," IEEE Trans. Antennas Propag., vol. 51, no. 3, pp. 421-429, Mar. 2003.

[3] J. Hirokawa, H. Arai, and N. Goto, "Cavity Backed Wide Slot Antenna," Proc. Inst. Elect. Eng. H, vol. 136, no. 1, pp. 29-33, Feb. 1989.

[4] H. Nakano, M. Iwatsuki, M. Sakurai, and J. Yamauchi, "Cavity Backed Rectangular Aperture Antenna With Application to a Titled Fan Beam Array Antenna," IEEE Trans. Antennas Propag., vol. 51, no. 4, pp. 712-717, Apr. 2003.

[5] W. Hong, N. Behdad, and K. Sarabandi, "Size Reduction of Cavity Backed Slot Antennas," IEEE Trans. Antennas Propag., vol. 54, no. 5, pp. 14611466, May 2006.

[6] J. Hirokawa and M. Ando, "Single-Layer Feed Waveguide Consisting of Posts for Plane TEM Wave Excitation In Parallel Plates," IEEE Trans. Antennas Propag., vol. 46, no. 5, pp. 625-630, May 1998.

[7] L.Yan, W. Hong, G. Hua, J. X. Chen, K.Wu, and T. J. Cui, "Simulation and Experiment on SIW Slot Array Antennas," IEEE Microw. Wireless Compon. Lett., vol. 14, no. 9, pp. 137-139, Sep. 2004.

[8] Z. C. Hao, W. Hong, J. X. Chen, X. P. Chen, and K. $\mathrm{Wu}$, "A Novel Feeding Technique for Antipodal Linearly Tapered Slot Antenna Array," in IEEE MTTS Int. Microw. Symp. Dig., vol. 6, pp. 12-17, 2005.

[9] G. Q. Luo, W. Hong, H. J. Tang, J. X. Chen, X. X. Yin, Z. Q. Kuai, and K. Wu, "Filtenna Consisting of Horn Antenna and Substrate Integrated Waveguide Cavity FSS," IEEE Trans. Antennas Propag., vol. 55, no. 1, pp. 92-98, Jan. 2007.

[10] G. Q. Luo, Z. F. Hu, L. X. Dong, and L. L. Sun, "Planar Slot Antenna Backed by Substrate Integrated Waveguide Cavity," IEEE Antennas and Wireless Propagation Letters, vol. 7, pp. 236-239, Aug. 2008.

[11] Cassivi Y., Perregrini L., Arcioni P., Bressan M., Wu K., and Conciauro G. "Dispersion Characteristics of Substrate Integrated Rectangular Waveguide," IEEE Microwave and Wireless Components Letters, vol.12, no. 9 , pp. $333-335,2002$.
[12] Bray, J. R. and L. Roy, "Resonant Frequencies of Post-Wall Waveguide Cavities," Proc. Inst. Elect. Eng., vol. 150, no. 10, pp. 365-268, Oct. 2003.

[13] M. Bozzi, L. Perregrini, and K. Wu, "Modeling of Conductor, Dielectric, and Radiation Losses in Substrate Integrated Waveguide by the Boundary Integral-Resonant Mode Expansion Method," Microwave Theory and Techniques, IEEE Transactions on, vol. 56, pp. 3153-3161, Dec. 2008.

[14] D. M. Pozar, Microwave Engineering, 2nd ed, New York: Wiley, 1998.

[15] N. Behdad and K. Sarabandi, "A Wide-Band Slot Antenna Design Employing A Fictitious Short Circuit Concept," IEEE Trans. Antennas Propag., vol. 53, no. 1, pp. 475-482, Jan. 2005.

[16] X. Chen, W. Hong, J. Chen, and K. Wu, "Substrate Integrated Waveguide Elliptic Filter With High Mode," APMC2005 Proceedings, vol. 1, 2005

[17] E. Ofli, R. Vahldieck, and S. Amari, "Novel E-Plane Filter and Diplexer With Elliptic Response for Millimeter-Wave Application," IEEE Trans., Microwave Theory Tech., vol. 53, pp. 843-851, March 2005.

[18] Y. Cassivi and K. Wu, "Low Cost Microwave Oscillator Using Substrate Integrated Waveguide Cavity," IEEE Microwave. Wireless Component. Letters, vol. 13, no. 2, pp. 48-50, Feb. 2003.

[19] F. F. He, K. Wu, W. Hong, L. Han, and X. Chen, "A Low Phase-Noise VCO Using an Electronically Tunable Substrate Integrated Waveguide Resonator," IEEE Trans., Microwave Theory Tech., vol. 58, no. 12, pp. 843-851, Dec. 2010. 